\title{
ANÁLISE HISTÓRICA SOBRE O DESENVOLVIMENTO DA BIBLIOTECONOMIA E CIÊNCIA DA INFORMAÇÃO DO LESTE EUROPEU NO PÓS-SEGUNDA GUERRA MUNDIAL (1945-ANOS 1960)
}

\author{
Roberto Lopes dos Santos Junior \\ Professor Adjunto da Faculdade de Arquivologia pela Universidade Federal do Pará \\ Doutor em Ciência da Informação pelo convênio IBICT / UFRJ \\ robertolopes@ufpa.br
}

\section{Resumo}

Pesquisa histórica, a partir de levantamento bibliográfico e revisão de literatura em fontes secundárias, que analisa o desenvolvimento dos campos em biblioteconomia e informação científica no leste europeu (Alemanha Oriental, Hungria, Polônia, Bulgária, Tchecoslováquia e Romênia), entre o final da Segunda Guerra Mundial até o fim dos anos 1960. O estudo inicialmente analisou a constituição e desenvolvimento das bibliotecas na região, entre a idade média até o fim da Segunda Guerra Mundial. Posteriormente discutiu-se o processo de reconstrução e reorganização das bibliotecas e dos cursos em biblioteconomia desses países após o conflito, e da constituição de institutos em informação científica na região sob influência do Instituto Estatal de Informação Científico e Técnica (VINITI) soviético. A pesquisa identificou que os acervos documentais desses países seguiram por um caminho de reestruturação que se manteria nas décadas seguintes, contudo muitas vezes assimilando, de forma impositiva, práticas e ideias produzidas por organismos e autores da União Soviética, o que continuou, de forma irregular, até o final da ocupação soviética na região, a partir de 1989.

Palavras chave: Biblioteconomia no Leste Europeu. Informação científica no Leste Europeu. Pós-Segunda Guerra Mundial

\section{HISTORICAL ANALYSIS ABOUT THE DEVELOPMENT OF LIBRARIANSHIP AND INFORMATION SCIENCE IN EASTERN EUROPE AFTER THE SECOND WORLD WAR (1945-1960S)}

\begin{abstract}
Historical analysis, based on the review of literature of secondary sources, identifying the development of scientific Information and Library Science in the Eastern Europe Countries (Eastern Germany, Hungary, Poland, Bulgaria, Romania and Czechoslovakia) between the ends of the Second World War until the second half of the 1960s. This work initially made a historical analysis about the constitution of libraries in these countries between the middle age until 1945. After it will made a analysis about the reconstruction and reorganization of the libraries and courses related to Library Science in these countries after the war, and the constitution of scientific information institutes in the region on the direct influence of soviet organisms, like, for example, the All-Russian Institute for Scientific and Technical Information (VINITI). The research identifies that the documentary collections in these countries follow a way of reconstruction that will continue decades after 1945, despite the imposition of ideas and practices made by the Soviet Union authors and organizations, action that continue, with irregularity, until the end of soviet occupation in the region in 1989.
\end{abstract}

Key-words: Library Science in Eastern Europe. Scientific information in Eastern Europe. Post second world war. 


\section{Introdução}

Maio de 1945, após quatro anos de conflito, com 27 milhões de mortos e cerca de 70 mil vilarejos, 1.700 cidades e 32 mil fábricas soviéticas destruídas, o exército da União das Repúblicas Socialistas Soviéticas ocupou Berlim, a capital alemã, derrotando os nazistas, e encerrando a Segunda Guerra Mundial. Alemanha oriental (consolidada em 1949), Hungria, Polônia, Bulgária, Tchecoslováquia e Romênia, libertadas e ocupadas pelas tropas soviéticas, teriam adotado entre 1948-49 o sistema comunista em seus governos como principal forma política (e, em diferentes maneiras, nos campos cultural e econômico), sendo "incorporados" ao que seria chamado de "órbita soviética" ou "bloco comunista" (ou "cortina de ferro", cunhada pelo político inglês Winston Churchill em 1946) (JUDT, 2008; SERVICE, 2009).

A implantação de elementos ideológicos comunistas, centralizados pelos ditames de Moscou, segundo pesquisas recentes (e.g. APPLEBAUM, 2012), se mostrou, inicialmente, gradativo, mas, após 1949, sendo imposta de forma cada vez mais agressiva nesses países, com suas populações mostrando ressentimento e, em alguns momentos, oposição direta a URSS, postura essa mantida por quase todo o período de ocupação soviética na região.

No âmbito dos acervos documentais (bibliotecas e arquivos), e da consolidação de organismos de informação no Leste Europeu nos primeiros anos pós-conflito, a presença soviética também fez se perceber de forma crescente, na tentativa da consolidação de uma espécie de "ciência da informação comunista".

As origens da Ciência da Informação (ou Informatika) na URSS são identificadas em medidas tomadas pelo líder bolchevique Vladimir Lênin na construção de um sistema de informação científica no país, entre 1918 a 1922, medidas essas que seriam consolidadas a partir dos anos 1920 e meados da década de 1930, com a criação de políticas de treinamento de profissionais que pudessem trabalhar com a literatura científica recebida e produzida no país. Contudo, a política cada vez mais repressiva promovida pelo dirigente soviético Josef Stalin, a partir de 1937, além da participação do país durante a Segunda Guerra Mundial, fizeram com muitos desses serviços fossem interrompidos. Com o final da guerra, a ascensão do país ao status de superpotência, além do início da guerra fria com os EUA, fizeram a URSS retomar e expandir suas pesquisas e iniciativas ligadas a informação, sendo a Europa oriental o primeiro local de "exportação" de iniciativas informacionais com um viés socialista e russo, com resultados que variaram entre os países da região (SANTOS JUNIOR; PINHEIRO, 2010).

Foi constatado, a partir da análise em periódicos brasileiros, carência de bibliografias que discutam como o campo da Ciência da Informação se desenvolveu no leste europeu. A 
tentativa de suprir, mesmo que parcialmente, essa lacuna, serviu de justificativa para o desenvolvimento desse trabalho.

A presente pesquisa, de forma preliminar, a partir de levantamento bibliográfico e revisão de literatura em fontes secundárias (artigos, comunicações, livros e capítulos de livros), analisou algumas características que marcaram a biblioteconomia e a Ciência da Informação do Leste Europeu entre o final da Segunda Guerra Mundial até os anos 1960. Inicialmente o texto discutiu as origens e evolução das bibliotecas e acervos documentais nesses países entre a idade média até 1945. Posteriormente analisou a reconstrução e reorganização desses acervos, além da reconstituição dos cursos em Biblioteconomia nessa região. Por fim, dados sobre a formação de um "bloco socialista" onde práticas e teorias ligadas à informação científica foram desenvolvidas, e muitas vezes impostas por Moscou, nos anos 1960, além da implantação de organismos e institutos responsáveis pela organização e armazenamento informacional no Leste Europeu, também foram discutidos.

\section{Breve contextualização dos acervos documentais do Leste Europeu até 1945}

Parte considerável dos países que formam atualmente a região da Europa central e oriental possuem uma história de reunificação e reorganização política relativamente recente, entre a segunda metade do século 19 e as primeiras décadas do século 20, advindas principalmente da reunificação alemã, em 1871, e do fim dos impérios austro-húngaro, russo e otomano na Primeira Guerra Mundial (KERSHAW, 2016). Contudo, a existência de acervos documentais nessa região, sejam arquivos e bibliotecas, é antiga, em alguns casos com origens na idade média.

Na Alemanha, as primeiras bibliotecas foram criadas entre os séculos nove e dez, na esteira de uma frágil reorganização política e cultural que o país sofria na época, onde, no século XVI, seriam criadas as “bibliotecas judiciais”, em Munique (1558) e Dresden (c.1556), importantes locais de aproximação dos acervos documentais com a elite letrada da época. Em Praga (parte do império alemão na época e capital da futura Tchecoslováquia), com a consolidação das primeiras universidades na região, a primeira biblioteca regional foi instituída em 1348 . Na Hungria, sob os auspícios do rei Matias I (c.1443-1490), criou-se a Biblioteca Corviniana, que, no fim do século XV, era a segunda maior biblioteca da Europa, servindo de base e inspiração para a criação da biblioteca nacional húngara, em 1803. Na Polônia, arquivos e bibliotecas seriam instituídos, com considerável controle do Império Russo, a partir de 1795. Na Romênia, após certo litigio sobre onde a biblioteca nacional deveria ser construída, a mesma foi 
inaugurada na capital Bucareste em 1859. Na Bulgária, a primeira biblioteca acadêmica, ligada à Academia de Ciências, foi criada em 1869, influenciando diretamente a construção da biblioteca nacional do país, nove anos depois (RHODES, 2002; ENACHE, 2007; WOJCICKA, 1957; NIKOLOVA-HOUSTON, 2009; SEEFELDT; SYRÉ, 2011).

Uma característica em comum aos acervos documentais desses países durante o século XIX e início do XX foi a limitada visitação a essas bibliotecas, devido à baixa alfabetização da população, incompletas e embrionárias legislações sobre a constituição, funcionamento e utilização desses locais, e da formação deficitária dos profissionais que trabalhavam nesses organismos. Os cursos em "organização de coleções" que vigoravam em diversas universidades dessa área davam apenas visões preliminares aos bibliotecários e arquivistas que trabalhavam nesses acervos (RÂPEANU; DOVÎNCÃ, 2007; NIKOLOVA-HOUSTON, 2009; WEHMER, 1964).

A Primeira Grande Guerra criou um período de incertezas para os conjuntos documentais da região. Contudo, apesar de acervos terem sido perdidos na Polônia, Alemanha e Rússia, a destruição mostrou-se localizada e sem grandes consequências, sendo que essas perdas seriam recuperadas, pelo menos parcialmente, nas décadas de 1920 e 1930 (BÁEZ, 2006).

Somente após a Primeira Guerra Mundial, em um período de agitação e autoritarismo político espreitando grande parte dessas nações, que leis e cursos especificamente ligados a biblioteconomia e arquivologia foram instituídos, de forma irregular, no Leste Europeu. Na Tchecoslováquia, as primeiras leis de bibliotecas e arquivos foram promulgadas logo após a criação do país, em 1919. Na Bulgária, os primeiros cursos em biblioteconomia foram criados também em 1919. Na Romênia o primeiro curso de Arquivologia e Paleografia foi instituído em 1925, e o de Biblioteconomia em 1932, ambos localizados nas cidades de Bucareste e Cluj (RÂPEANU; DOVÎNCÃ, 2007; WOJCICKA, 1957; NIKOLOVA-HOUSTON, 2009).

A situação alemã, contudo, foi mais delicada. As primeiras tentativas de legislação e criação de cursos no país datam de 1891. Porém, com a ascensão do regime nazista, em 1933, modificações na legislação permitiram a apreensão e queima, muitas vezes em locais públicos, de obras consideradas "subversivas" ou contrárias a realidade política existente, além da centralização dos acervos documentais, e de uma ideologização cada vez mais agressiva nas bibliotecas, museus e arquivos, por vezes com interferência direta de funcionários e dirigentes nazistas (WEHMER, 1964; BÁEZ, 2006). Bulgária, Romênia e Hungria, aliados ao regime alemão e também possuindo governos de cunho ditatorial, adotaram políticas semelhantes de controle e censura, apesar de intensidade bem menor que a do regime nazista (BÁEZ, 2006). 
A Segunda Guerra Mundial teve uma consequência sombria para as bibliotecas e arquivos de parte considerável do Leste Europeu, visto que a região sofreria as piores e mais destrutivas batalhas do conflito. Tanto a Polônia, invadida em 1939 e sofrendo violenta retaliação e ocupação por tropas nazistas, quanto a Alemanha, que sofreria bombardeios constantes dos aliados e uma invasão e retaliação (muitas vezes implacável) soviética, tiveram bibliotecas, arquivos e museus destruídos (os dados exatos sobre a extensão das perdas continuam em debate), com conjuntos documentais fragmentados, danificados e saqueados (NICHOLAS, 2010; BÁEZ, 2006). Ambos os países só conseguiram, a duras penas, recuperar parte considerável desses acervos na segunda metade dos anos 1990 (GRIMSTEAD, 2002, 2010).

Em um ambiente de destruição, onde todos os países do Leste Europeu, em maior ou menor medida, tiveram perdas estruturais consideráveis, e da imposição soviética na região, inicia-se uma fase "socialista" para seus conjuntos documentais.

\section{Reorganização e reconstrução: a biblioteconomia do Leste Europeu no pós-guerra}

Em relação às bibliotecas e arquivos no Leste Europeu, muitos danificados pelos violentos embates entre os exércitos nazista e soviético, algumas alternativas foram seguidas por esses países para a reconstrução dos seus acervos.

Essas nações tiveram, por um lado, que adotar políticas de centralização de seus conjuntos documentais, o que muitas vezes significou a perda de poder de alguns bibliotecários para organismos políticos ligados ao partido comunista. Por outro lado, esses países, no final dos anos 1950, além de terem recuperado grande parte de seus conjuntos documentais, obtiveram também legislações que melhor regulamentaram o funcionamento de suas bibliotecas e arquivos, além da delimitação do papel dos bibliotecários e arquivistas nessas instituições $^{1}$ (RHODES, 2002; ENACHE, 2007; WOJCICKA, 1957; NIKOLOVAHOUSTON, 2009).

A Bulgária teria sua nova legislação ligada aos acervos biblioteconômicos e arquivísticos promulgado em 1953, seguidos pela Romênia, promulgada em 1955, a

\footnotetext{
${ }^{1}$ Contudo, informações sobre a constituição dos acervos das bibliotecas do leste europeu nesses anos mostram-se obscuras na bibliografia levantada, focando muito nos saques e perdas oferecidos pelos soviéticos em detrimento de dados sobre a reconstrução dos mesmos (exceção a essa abordagem pode ser localizada em Rojni, 1964, que apresentou maiores informações sobre a reconstituição das bibliotecas nacionais e regionais nesses países). Applebaum (2012), focando na Hungria, Polônia e Alemanha oriental, cita, de forma localizada, que algumas bibliotecas deram prioridade a aquisição de obras relacionadas ao marxismo e comunismo, ligadas aos ditames dos governos comunistas e da URSS. Hobsbawn (2011) cita a considerável participação de bibliotecas e arquivos da Alemanha oriental na produção de uma das primeiras tentativas de publicação integral da obra de Karl Marx e Friedrich Engels, chamadas de Werke e publicadas originalmente em 1956.
} 
Tchecoslováquia, reestruturada em 1959, e a Polônia, que teria legislações esparsas promulgadas durante toda a década de 1950. Essas legislações, de forte caráter estatal e centralizador dos acervos documentais, coincidiram com a reinauguração das bibliotecas e arquivos nacionais, com suporte e coordenação de profissionais e instituições soviéticas (RHODES, 2002; ENACHE, 2007; WOJCICKA, 1957; NIKOLOVA-HOUSTON,2009).

A partir de meados dos anos 1960, as práticas de organização das bibliotecas nacionais nesses países seriam feitas a partir dos ditames do principal organismo em biblioteconomia na União Soviética, a Biblioteca Estatal Lenin (atual Biblioteca Estatal da Rússia) (RICHARDS, $1998 ; 1999)$.

Em relação a Alemanha oriental, depois de certa confusão e "reorganização" nos primeiros anos do pós guerra, marcado por trocas confusas de documentos, informações desencontradas dos acervos nas diferentes partes ocupadas do país (GAGLIARDO, 1957), além dos consideráveis saques (ou "reparações") feitas pelas tropas soviéticas entre 1945- 49 - com cerca de um milhão e quinhentos mil livros e documentos enviados para arquivos e bibliotecas da URSS (RICHARDS, 1996) -, o país, a partir de 1952, reorganizaria as funções de suas bibliotecas regionais, além do estímulo da construção de dezenas de outras bibliotecas e arquivos em diferentes partes do país nas décadas seguintes (SEEFELDT; SYRÉ, 2011).

Além das bibliotecas e arquivos, no fim dos anos 1940, os países do Leste Europeu tiveram reconstruídos e reformulados seus cursos de graduação em biblioteconomia. O funcionamento e constituição desses cursos variaram de país para país.

Na Romênia, os cursos de Biblioteconomia (muitas vezes inseridos em programas ligados a filologia, arquivologia e paleografia), no período entre 1948-1960, tiveram uma existência instável, com tensões e contendas sobre o campo de atuação das áreas em biblioteconomia, arquivologia, paleografia, documentação e Ciência da Informação, além de interrompidos ocasionalmente, e somente perto do final do regime comunista com sua estrutura melhor delineada. (ENACHE, 2007);

Na Alemanha Oriental (instituída em 1952), o forte centralismo seria uma característica marcante na formação de bibliotecários no país, característica essa diminuindo gradativamente a partir de meados dos anos 1960. A lógica desses cursos era que o formando na capital Berlim oriental tivesse autonomia para trabalhar ou coordenar as bibliotecas regionais do país, onde os formandos das universidades regionais serviriam de suporte as iniciativas e projetos propostos pela capital (RUCKL, 1993; WEHMER, 1964).

Na Polônia (instituído em 1951), e Hungria (1949), os cursos transitavam, de forma delicada, entre visões ligadas ao marxismo-leninismo e materialismo dialético com teorias e 
ideias de autores norte-americanos e da Europa Ocidental, criando certa confusão nos currículos dos cursos nesses países, além de constante antagonismo contra professores com visões mais ocidentais, sendo eles recebendo posturas de hostilidade e retaliação nas universidades ou, em alguns casos, pelo governo ${ }^{2}$ (DRZEWIECKI; ZYBERT, 1995; PÁLVÖLGYI, 2000).

Em relação à Bulgária, a imposição de ideias socialistas nos cursos mostrou-se intensa e agressiva, onde os soviéticos tentaram excluir elementos ocidentais no país, o que, no fim do regime comunista, mostrou-se parcialmente malsucedido, graças a iniciativas de pesquisadores como, por exemplo, Todor Borov (1901-1993), que ajudaram na constituição dos currículos desses cursos no país a partir dos anos 1950, habilmente transitando entre diferentes correntes de pesquisa (NIKOLOVA-HOUSTON, 2009);

$\mathrm{Na}$ Tchecoslováquia, iniciativas dos organismos de informação e cursos de Biblioteconomia, e a atuação de pesquisadores como, por exemplo, Augustin Merta (19142006), permitiram que o país pudesse oferecer trabalhos de considerável qualidade tanto para a Biblioteconomia quanto para a Ciência da Informação, produção essa parcialmente diminuída a partir dos anos 1970, em consequência da invasão soviética ao país em 1968 (KOFNOVEC, 2004).

Apesar de considerável isolamento, tanto a Biblioteconomia quanto cursos ligados à informação científica nesses países, por motivos muitas vezes pragmáticos, utilizaram ideias e conceitos de autores fora da cortina de ferro. As ideias de documentação do pesquisador belga Paul Otlet, a classificação facetada, proposta pelo bibliotecário indiano Shiyali Ranganathan, e até conceitos ligados a epistemologia social (estudo das dimensões sociais do conhecimento e da informação), do norte-americano Jesse Shera seriam encontrados em alguns currículos de biblioteconomia da região (CHOLDIN, 2005).

Mesmo com essas diferenças, os cursos de Biblioteconomia, pelo menos entre os anos 1950 e 1960, se assemelhavam em um importante aspecto: os currículos davam preferência a formação prática dos bibliotecários, com atenção apenas localizada em aspectos mais teóricos da área. Como consequência, durante os anos 1970, os bibliotecários não esconderiam críticas, inicialmente reservadas, porém cada vez mais constantes, sobre o caráter excessivamente tecnicista de sua formação, onde, apesar de pretensas "polêmicas" teóricas, no geral, existia pouco espaço para análises mais epistemológicas, com o profissional em bibliotecas desses

\footnotetext{
${ }^{2}$ Em parte, esse clima instável ecoava na própria situação política desses países, sendo ambos os que mais se opuseram as vezes de forma veemente à ocupação soviética, visualizada, por exemplo, na rebelião húngara de 1956, repelida de forma violenta por tropas da URSS, e nos protestos, de grandes proporções, ocorridos na Polônia em 1956, 1970 e 1980-81.
} 
países treinado para "consolidar a reorganização" dos acervos biblioteconômicos (JOHNSON, 1984; DRZEWIECKI, ZYBERT, 1995; PÁLVÖLGYI, 2000; RÂPEANU, DOVÎNCÃ, 2007).

Houve exceções, especificamente na Alemanha Oriental, que nesse período, seus cursos tiveram palestras de filósofos como Jürgen Habermas, disciplinas ministradas pelo cientista da informação Gernot Wersig, que manteve relação com ideias apresentas nos Leste Europeu e URSS, além de edições especiais dos periódicos Mitteilungsblatt des Verbandes der Bibliotheken des Landes Nordrhein-Westfalen Bibliotheksdienst und Bibliographie, Bibliotheksdienst, Zentralblatt for Bibliothekswesen, e Bibliothek: Forschung und Praxis, que uniam pesquisas em biblioteconomia das duas Alemanhas, e eventos em conjunto a partir dos anos 1980. Porém, essas iniciativas foram localizadas e pouco tiveram influência para o maior aprimoramento teórico da área no país (LEHMANN, 1995).

\section{Construindo a Informação científica "socialista"}

A ofensiva soviética em "unificar" as redes de informação e os centros de documentação no Leste Europeu, influenciado pelos primeiros anos da guerra fria e do entrincheiramento dos campos político e econômico entre a Europa ocidental e oriental, ocorre no final dos anos 1940, mais especificamente com a criação do Conselho para Assistência Econômica Mútua (COMECON), em 1949, que visava a integração econômica das nações do Leste Europeu.

Zunde (1969) e Richards (1999) citam a existência de projetos de cooperação entre as bibliotecas e arquivos nacionais desses países, incluindo a constituição de conferencias e congressos, reuniões bianuais com os diretores desses organismos, visitas e cursos entre profissionais, eventos de divulgação, além de projetos de automação dos serviços de informação e de preservação dos acervos documentais.

Em 1963, o COMECON instituiu a Comissão Permanente de Coordenação das Pesquisas Técnicas e Científicas, unindo bibliotecas, universidades e instituições de pesquisa da região, estimulando a publicação de periódicos ligados à Informação Científica, além da publicação de vocabulários, dicionários técnicos e revistas de resumo de trabalhos científicos (essa última em ampla publicação e utilização na URSS desde 1953) (RICHARDS, 1998; ZUNDE, 1969).

Em relação ao campo de informação científica, um importante marco aconteceria com a criação, em junho de 1952, do Instituto Estatal de Informação Científica e Técnica, ou VINITI, espécie de "órgão central” que coordenou a maior parte das pesquisas e projetos ligados à Ciência da Informação na URSS (SANTOS JUNIOR, PINHEIRO, 2010). Em seus 
primeiros anos, o instituto reorganizou organismos e publicações ligadas à informação científica no Leste Europeu.

Chernyi (2005) afirma que o VINITI enviou dezenas de especialistas para a região, e que vários profissionais desses países foram para a URSS se especializar em cursos ou programas de treinamento feitos pelo instituto, além da criação de organismos nessas nações em que sua estrutura e serviços se assemelhassem ao VINITI. O autor afirma a existência de uma troca "fraterna" entre o campo em Ciência da Informação soviético com o Leste Europeu, mas admitiu, discretamente, que a URSS muitas vezes ignorou necessidades e particularidades dos países da região ao implementar políticas de informação nos mesmos.

Mikhailov, Chernyi e Gilyareviskyi ([1968] 1973), ao relatarem o estado da arte do campo em informação nos países do Leste Europeu no final dos anos 1960, apresentaram que boa parte deles possuíam institutos que, indiretamente, lembravam o VINITI soviético: na Alemanha oriental, o Instituto Central de Informação e Documentação (instituído em 1963); na Polônia, o Instituto Central de Informação Científica, Técnica e Econômica (instituído em 1961); na Tchecoslováquia, o Centro de Informação Científica, Técnica e Econômica; na Bulgária, o Instituto Central em Informação Científica (instituída em 1962); e na Romênia, o Instituto Central de Documentação Técnica. Os autores não escondem, apesar dos elogios ao funcionamento dessas instituições, que as mesmas seguiam tarefas e procedimentos padronizados, centralizados e ditados em Moscou.

Essa centralização seria percebida, e "festejada" por alguns pesquisadores da região, nos congressos que reuniam o diretor do VINITI com os desses organismos, sendo ocorridos oitos deles entre 1964 e 1979, com seus anais identificando tentativas soviéticas de criar uma "rede de informação científica" unindo a URSS e o Leste Europeu (RICHARDS, 1999). Contudo, pelo menos no âmbito da criação de uma rede automatizada de informação científica, focada principalmente no Sistema Estatal de Gerenciamento Automatizado (em russo, OGAS) - uma tentativa do bloco comunista de se opor a Arpanet estadunidense-, pela limitação dos modelos de computadores usados, bem como políticas equivocadas do Partido Comunista, as iniciativas mostraram-se limitadas e ineficientes, sendo encerradas, após longa inatividade, em 1998 (SANTOS JUNIOR, 2013).

Em 1969, esses institutos foram inseridos na Rede Internacional de Informação Científica (MSNTI), na qual a URSS tentava suprir os países sob sua influência de material científico publicado nos países ocidentais, além de tentar centralizar e padronizar os serviços em informação no bloco comunista (SANTOS JUNIOR; PINHEIRO, 2010). 
Na edição de dezembro de 1966, o periódico soviético Nauchno-Tekhnicheskaya Informatsiya publicou um artigo de autoria do pesquisador e então diretor do VINITI, A. I. Mikhailov, com a colaboração dos autores A. I. Chernyi e R. S. Gilyareviskyi, intitulado "Informatika: um novo nome para a teoria da informação cientifica". Nesse artigo, os autores apontavam o surgimento de uma nova disciplina, denominada Informatika, apresentada como

Disciplina científica que estuda a estrutura e as propriedades (não especificamente o conteúdo) da informação científica, assim como as leis que regem as atividades ligadas à informação cientifica, sua teoria, história, metodologias e organização. O objetivo da Informatika é a de desenvolver métodos e meios eficientes de registro, processamento analítico sintético, armazenamento, recuperação e disseminação da informação científica (MIKHAILOV, 1967, p. 241).

Segundo os autores, a Informatika trabalha ligada a dois principais objetos de análise: a informação científica, ou "Informação lógica obtida durante o processo de conhecimento, o qual reflete adequadamente as leis do mundo objetivo e se utiliza na prática histórico-social" (MIKHAILOV, 1967a, p.239-240) 33; e a informação social, caracterizada pela informação que, após sua organização e disseminação, teria algum tipo de utilização pela sociedade e organismos político-econômicos ${ }^{4}$ (SANTOS JUNIOR, 2010).

Houveram inclusões de conceitos ligados a essa disciplina científica, além dos termos Informação científica e social, em cursos de formação de bibliotecários e documentalistas na região. Richards (1992; 1998) e Chernyi (2005) afirmam que, entre o final dos anos 1960 e por quase toda a década seguinte, especializações e mestrados ligados a Informação Cientifica/ Informatika/ Ciência da Informação ${ }^{5}$ foram consolidados nesses países, e pesquisadores soviéticos como A. D. Ursul, Yuri Schreider e Ruggero Gilyareviskii ministraram disciplinas, onde uma "filosofia/epistemologia da informação" socialista foi apresentada. Os cursos de graduação em Biblioteconomia, curiosamente, tiveram pouca inserção da Informatika em seus

\footnotetext{
${ }^{3}$ Para uma breve análise sobre a utilização do conceito na URSS ver Santos Junior e Pinheiro, 2010.

${ }^{4}$ Em relação ao conceito de informação social, existiram correntes divergentes na URSS, a primeira ligada às ideias de A. I. Mikhailov e colaboradores, e, a partir dos anos 1970, ideias ligadas ao pesquisador A. V. Sokolov, que propunha o afastamento de análises ligadas à informação científica e a criação de uma Informatika social, baseada na prática social, na observação da sociedade, e na interligação da área com a Biblioteconomia, Arquivologia e Museologia. Ambos os conceitos seriam utilizados tanto na URSS quanto no Leste Europeu (com as ideias de Sokolov amplamente utilizadas na Tchecoslováquia e Hungria, e as de Mikhailov no resto do bloco), porém cairiam em desuso e substituídas por outras ideias após o comunismo. Para uma análise sobre a constituição e utilização desse conceito, ver o trabalho de Smutny (2015).

${ }^{5}$ As três terminologias seriam revezadas na denominação dos cursos, criando em alguns momentos confusão na constituição dos mesmos.
} 
currículos, e somente depois do comunismo discutiriam a mudança de sua denominação, incluindo o termo Ciência da Informação em seu escopo.

Parte considerável dos coordenadores e profissionais responsáveis por organismos documentais nesses países fariam suas especializações, mestrado e doutorados em cursos ligados ao VINITI - como o mestrado em Informação Científica, instituído em 1959 -, e em organismos como o Instituto Krupskaya para a cultura de Leningrado - atualmente Academia de Cultura de São Petersburgo-, e o Instituto para a Qualificação de Profissionais da Informação (IPKIR), todos os três recebendo, até o início dos anos 1990, diferentes estudantes de todo o bloco comunista (SANTOS JUNIOR, PINHEIRO, 2010).

Contudo, a inserção de elementos socialistas não impediu que institutos ou pesquisadores participassem de eventos internacionais ligados a Federação Internacional de Associações e Instituições Bibliotecárias (IFLA) (além de visita ocasional de pesquisadores ocidentais como, por exemplo, os ingleses Douglas Foskett ${ }^{6}$, Bertram Brookes ${ }^{7}$ e Derek de Solla Price $^{8}$ nesses países), e da participação no Comitê de Estudos sobre Pesquisa de Base Teórica da Informação, ou FID/RI, ligado a Federação Internacional de Documentação, em atividade entre 1965-1989, que teve como objetivo analisar e discutir questões teóricas da Informatika /Ciência da Informação. Por mais que conceitos e práticas soviéticas fossem apresentadas e implementadas, não interessava um isolamento total do bloco comunista na troca de teorias e iniciativas práticas com os países capitalistas (SANTOS JUNIOR, PINHEIRO, 2010; RICHRADS, 1998).

Em casos localizados, aconteceria o fenômeno oposto, do campo de pesquisa soviético utilizando ideias originalmente propostas por países do Leste Europeu como, por exemplo, na utilização de conceitos ligados a Ciência da Ciência ${ }^{9}$, disciplina científica proposta originalmente na Polônia na década de 1930, que permitiu a reestruturação de estudos quantitativos sobre a ciência soviética, em publicações a partir do final dos anos 1950 e em congressos- em especial o $11^{\circ}$ Congresso de Historiadores da Ciência de Varsóvia, em 1965, e no simpósio Soviético / Polonês ocorrido em Lviv (Ucrânia), em junho de 1966 -, onde buscouse analisar e definir a estrutura tanto da Ciência da Ciência quanto dos estudos quantitativos,

\footnotetext{
${ }^{6}$ (1918-2004) bibliotecário e cientista da informação.

7 (1910-1991) estatístico e cientista da informação.

${ }^{8}$ (1922-1983) físico e historiador da ciência.

9 Segundo os pesquisadores Maria Ossowska e Stanislaw Ossowski, principais precursores da disciplina na Polônia, essa nova disciplina teria o objetivo de "(...) ensinar o que é a ciência, contribuindo para formar nos pesquisadores concepções sobre o que é a ciência, ao mesmo tempo influenciando sua criatividade" (OSSOWSKA, OSSOWSKI, [1936] 1964, p.82). Os autores inicialmente apresentaram quatro subáreas que constituem essa disciplina: Filosofia da Ciência, Psicologia da Ciência, Sociologia da Ciência, e estudos relacionados a problemas de caráter organizacional, práticos e históricos (OSSOWSKA, OSSOWSKI, [1936] 1964).
} 
disciplina essa denominada na URSS de Cientometria, a partir de 1966 (SANTOS JUNIOR, 2016).

\section{Considerações finais}

A partir de 1989, após anos de intempéries econômicas e políticas, além da dificuldade de Moscou em manter seu domínio nessas áreas, findava-se a ocupação soviética no Leste Europeu, onde os governos dessas nações, nesse ano, deixaram de seguir o regime comunista, selando a separação com a URSS (que, de forma abrupta, também deixaria o comunismo e seria dissolvida em dezembro de 1991) com o fim do COMECON (junho de 1991) e da aliança militar entre a URSS e o Leste Europeu, o Pacto de Varsóvia (julho de 1991) (JUDT, 2008).

A partir dos anos 1990, os países do Leste Europeu, de forma diferenciada, seguiram por um caminho de abertura, com projetos de cooperação com os Estados Unidos, China e União Europeia, além de desenvolverem e estimularem ideias e práticas próprias ligadas a Biblioteconomia e Ciência da Informação, não existindo mais as antigas amarras que limitavam essas áreas na região (JELUSIC, 2005). Com a entrada desses países tanto na União europeia quanto na Organização do Tratado do Atlântico Norte, programas de informatização de seus acervos, além da inclusão de organismos e institutos (reorganizados, renomeados e encerrando a longa relação existente com o VINITI) em eventos, ligados principalmente à Alemanha, França e Inglaterra, foram consolidados. Apesar de sensíveis a crise econômica que assola o continente desde 2008, o Leste Europeu colheu frutos de uma realidade informacional mais diversificada tanto no âmbito teórico quanto prático (LENKART, 2016).

A presente pesquisa analisou o desenvolvimento da Ciência da Informação e biblioteconomia no Leste Europeu durante as primeiras décadas do pós-segunda guerra, identificando as principais características apresentadas por essas áreas nesses países.

Em um primeiro momento percebe-se, por um lado, que, apesar dos danos e destruição advindos do conflito, os acervos documentais desses países puderam se reorganizar e seguir num caminho de reestruturação que se manteria nas décadas seguintes, visualizados em novas legislações, em reformuladas bibliotecas, em cursos de Biblioteconomia e em centros de pesquisa e estudo. Existiram empecilhos, principalmente num aparente caráter tecnicista que prejudicou uma maior diversificação teórica das graduações e das práticas bibliotecárias, porém, problema esse chegando a guisa de resolução com o fim do comunismo, mesmo que exista a necessidade de outras pesquisas que corroborem essas afirmações. 
Por outro lado, foi percebido que práticas e ideias produzidas por organismos e autores soviéticos seriam assimiladas, ou melhor, impostas, em diferentes países ligados a esfera de influência da URSS, onde, no fim, foi identificado que essa política "imperial" se mostrou irregular e não totalmente bem-sucedida, sendo que grande parte da Informatika não sobreviveria nessa região após o fim do domínio soviético. A Ciência da Informação nessa região não se mostrou totalmente isolada ou dependente das ideias soviéticas, visualizados, por exemplo, em iniciativas ligadas a Tchecoslováquia, que conseguiu oferecer alternativas para a Informatika. Contudo, não se ignora que a mão pesada de Moscou foi sentida. A Informação científica no Leste Europeu, por décadas, caminhou por um viés socialista e marxista-leninista, apenas ocasionalmente se inter-relacionado com o bloco capitalista.

Conclui-se que o Leste Europeu foi o primeiro local onde a URSS pode "experimentar" sua interpretação ligada à Ciência da Informação, porém, como em outras regiões ligadas ao bloco comunista, essa experimentação encontrou limites, principalmente em não se relacionar com as necessidades e características internas dessas nações, falha essa se mostrando fatal para a continuidade da Informatika após o comunismo, restringindo-se, após 1991, a Rússia e algumas ex-repúblicas soviéticas.

\section{Referências}

APPLEBAUM, A. Iron Curtian: the crushing of the eastern Europe (1944-1956). Londres: Penguin Books, 2012.

BÁEZ, F. História universal da destruição dos livros: das tábuas sumérias à guerra do Iraque. Rio de Janeiro: Ediouro, 2006.

CHERNYI, A. I. Российская академия наук - Всероссийский институт научной и технической информации. Moscou: Nauka VINITI, 2005. Disponível em: http://www.viniti.ru/download/russian/VINITI.50.Year.2005.pdf acesso em 29/03/2017

CHOLDIN, M. T. Libraries in continental Europe: the 40s and the 90s. Journal of Documentation, v. 61, n. 3, p. 356-361, 2005.

DRZEWIECKI, M.; ZYBERT, B. Training for Librarianship at the Academic Level in Poland. Journal of Education for Library and Information Science, v.36, n.1, p.66-71, 1995.

ENACHE, I. Problems of Romanian Librarianship: Romanian Librarianship on the Verge of European Integration. World Libraries, v. 17, n. 1, 2007.

GAGLIARDO, J. Archives in East Germany. The American Archivist, v. 20, n.3, p.209213, 1957. 
GRIMSTEAD, P. K. Legalizing "Compensation" and the Spoils of War: The Russian Law on Displaced Cultural Valuables and the Manipulation of Historical Memory. International Journal of Cultural Property, v. 17, p.217-255, 2010.

GRIMSTEAD, P. K. Russia's Trophy Archives: Still Prisoners of World War II? Open Society Archive, Central European University, Budapeste, 2002.

HOBSBAWN, E. Como mudar o mundo: Marx e o marxismo 1840- 2011. São Paulo: Companhia das Letras, 2011.

JELUSIC, S. Publishers and librarians in Central and Eastern Europe - love or hatred? Interlending \& Document Supply, v. 33, n. 1, p.19 - 25, 2005.

JOHNSON, I. M. Education and Training of Library Technicians in Czechoslovakia. International Library Review, v.16, n.3, 247-270, 1984.

JUDT, T. Pós-guerra: uma história da Europa desde 1945. Rio de Janeiro: Objetiva, 2008. KERSHAW, I. De volta do inferno: Europa 1914-1949. São Paulo: Companhia da Letras, 2016.

KOFNOVEC, L. Ing. Augustin Merta, Csc., doyen eeské informaení vidy. Narodní Knihovna, v. 15, n.3, p. 172-174, 2004.

LEHMANN, S. Library Journals and Academic Librarianship in Germany: A Sketch. College \& Research Libraries, v.56, n.4, p.301-312, 1995.

LENKART, J. Current Trends in Research Resources from Russia, Eastern Europe, and Eurasia: Implications for Reference Services and Resource Sharing. Slavic \& East European Information Resources, v. 17, n.4, p. 215-225, 2016.

MIKHAILOV, A. I. Informatics - A Scientific Discipline. Documentação e Informação Científica, Lisboa, v. 10, n. 53, p. 239-242, 1967.

CHERNYI, A. I. \& GILYAREVSKY, R.S. Fundamentos de la informatica. La Habana: IDICT/Academia de Ciencias de Cuba, Havana, 1973, 2 v.

NICHOLAS, L. H. Europa saqueada: o destino dos tesouros artísticos europeus no terceiro reich e na Segunda Guerra Mundial. São Paulo: Companhia das Letras, 2010.

NIKOLOVA-HOUSTON, T. Bulgarian librarianship: Surviving change through international cooperation. Advances in Library Administration and Organization , v. 27, p.49-71, 2009.

OSSOWSKA, M.; OSSOWSKI, S. The science of science. Minerva, v. 3, n. 1, p. 72-82. 1964.

Pálvölgyi, M. Library and information education and research in Hungary. Bibliothek, v.24, n.1, p.53-62, 200.

RHODES, R. Libraries, Librianship and Library Education in the Czech Republic. Dissertação de mestrado (biblioteconomia), Universidade de Norte Carolina, Estados Unidos, 2002.

RÂPEANU, A. C.; DOVÎNCÃ, C. Education for Library Professionals in Romania. INFORUM 2007: Conference on Professional Information Resources, 13. Proceedings. p.117, 2007. Disponível em: 
<https://www.academia.edu/3838952/Education_for_Library_Professionals_in_Romania>. Acesso em: 29 mar. 2017.

RICHARDS, P. S. Education for Information Science in the Soviet Union. Annual Review of Information Science and Technology (ARIST), New Jersey, p.267-290, 1992.

RICHARDS, P. S. Scientific information for stalin's laboratories, 1945-1953. Information Processing \& Management, v. 32, n. 1, p. 77-88, 1996.

The Reconfiguration of International Information Infrastructure Assistance since 1991. ASIS Bulletin, Junho/julho 1998. Disponível em: <http://www.asis.org/Bulletin/Jun98/richards.html>. Acesso em 29 mar. 2017.

The Soviet Overseas Information Empire and the Implications of its Disintegration.

In: History and Heritage of Science Information Systems. 1998 Conference Proceedings, p. 206-214, 1999.

ROJNI, M. University Libraries in Yugoslavia, Czechoslovakia, Hungary, Rumania, and Bulgaria. Library Trends, v. 12, n.4, p.583-604, 1964.

RUCKL, G.; RUCKL, S. German Democratic Republic (1949-1990). In: WEGERWORTH, R. (org.) World Encyclopedia of Library and Information Services, Illinois: American Library Association, p. 318-321, 1993.

SEEFELDT, J.; SYRÉ, L. Portals to the Past and to the Future - Libraries in Germany. Hildesheim, Zurique e Nova York: Georg Olms Verlag, 2011.

SANTOS JUNIOR, R. L. Analise da terminologia soviética "Informatika" e da sua utilização nas décadas de 1960 e 1970. In: XI Encontro Nacional de Pesquisa em Ciência da Informação, Rio de Janeiro, 2010.

SANTOS JUNIOR, R. L. A Informática vermelha: uma história do sistema computacional na ex-União Soviética. Ciência Hoje, v. 52, p. 22-25, 2013.

SANTOS JUNIOR, R. L. Metrias da comunicação e informação científicas e a contribuição dos pesquisadores da União Soviética e Rússia. Jundiaí: Paco Editorial, 2016.

SANTOS JUNIOR, R. L. PINHEIRO, L. V. R. A infra-estrutura em informação científica e em ciência da informação na antiga União Soviética (1917-1991). Encontros Bibli (Online), v. 15, p. 24-51, 2010.

SERVICE, R. The Penguin history of modern Russia: from tsarism to the twenty-first century. 3 ed. Londres: Penguin Books, 2009.

SMUTNY, Z. Social informatics as a concept: Widening the discourse. Journal of Information Science, v. 42, n.5, p.1-30, 2015.

WEHMER, C. The Organization and Origins of German University Libraries. Library Trends, v.12, n.4, p.480-512, 1964.

WOJCICKA, J. The Preservation of the State Records in Poland. The American Archivist, v. 20, n. 3, p. 195-199, 1957.

ZUNDE, P. Co-operation of the information agencies of the CMEA countries. International Library Review, v. 1, n. 4, p. 487-509, 1969. 